\title{
(6) OPEN ACCESS \\ The mental health of UK ex-servicemen with a combat-related or a non-combat-related visual impairment: does the cause of visual impairment matter?
}

\author{
Sharon A M Stevelink, ${ }^{1}$ Estelle M Malcolm, ${ }^{1}$ Pashyca C Gill, ${ }^{2}$ Nicola T Fear ${ }^{1,3}$
}

\begin{abstract}
${ }^{1}$ Department of Psychological Medicine, King's Centre for Military Health Research (KCMHR), King's College London, London, UK ${ }^{2}$ King's College School of Medicine, King's College London, London, UK ${ }^{3}$ Academic Department of Military Mental Health, Department of Psychological Medicine, King's College London, London, UK
\end{abstract}

\section{Correspondence to}

Dr Sharon Stevelink,

Department of Psychological Medicine, KCMHR, King's

College London, Weston Education Centre

10 Cutcombe Road, London SE5 9RJ, UK; sharon.stevelink@kcl.ac.uk

Received 12 August 2014 Revised 21 January 2015 Accepted 25 January 2015 Published Online First 23 April 2015
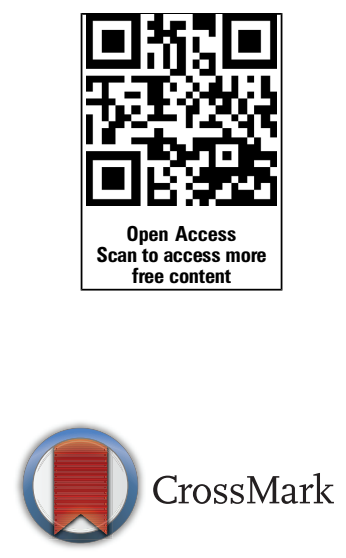

\footnotetext{
To cite: Stevelink SAM, Malcolm EM, Gill PC, et al. $\mathrm{Br} J$ Ophthalmol 2015;99:1103-1108.
}

\section{ABSTRACT}

Aims Since the start of the conflicts in Iraq and Afghanistan, the numbers of young service personnel who have sustained a combat-related visual impairment have increased. This cross-sectional study examined the mental well-being of ex-servicemen (aged 22-55 years) with a visual impairment and determined if the mental health of those with a combat-related visual impairment differed from those whose visual impairment is not combat-related.

Methods Male ex-service personnel with a visual impairment completed a telephone interview assessing the presence of depressive symptomatology, probable anxiety disorder, post-traumatic stress disorder (PTSD) symptomatology and alcohol misuse. Data were analysed using descriptive statistics.

Results 77 participants were included in the study, reflecting a response rate of $76.2 \%$. Of those with complete data ( $n=74), 20$ ex-servicemen had a combatrelated visual impairment. Among ex-service personnel with a combat-related visual impairment, 10.0\% (95\% $\mathrm{Cl} 0$ to 23.2) screened positive for a probable depression, $25.0 \%$ (95\% Cl 6.0 to 44.0$)$ for probable anxiety and $10.0 \%$ (95\% Cl 0 to 23.2 ) for probable PTSD. The prevalence of probable depression and probable PTSD differed among those with a non-combatrelated visual impairment, namely $18.5 \%$ (95\% Cl 8.1 to 28.9 ) and $16.7 \%$ (95\% Cl 6.8 to 26.7$)$, respectively. Probable anxiety was $18.5 \%(95 \% \mathrm{Cl} 8.1$ to 28.9$)$ among non-combat-related visually impaired ex-service personnel. $45.0 \%$ (95\% Cl 23.2 to 66.8$)$ of combatrelated visually impaired personnel reported hazardous drinking, compared with $20.4 \%$ (95\% CI 9.7 to 31.2 ) of those with a non-combat-related visual impairment. Conclusions Mental health problems were prevalent among visually impaired younger ex-servicemen. No statistically significant differences were found in the prevalence of mental health problems among exservicemen with a combat-related visual impairment compared with those with a non-combat-related visual impairment.

\section{INTRODUCTION}

Becoming visually impaired may have negative effects on the general health, mental well-being and quality of life of those affected. Qualitative evidence on the impact of visual impairment among older people indicated that the ability to independently perform daily activities was seriously hampered. $^{1}$ Impaired psychosocial well-being was reflected by the onset of depression, decreased self- esteem, fear of further deterioration of sight and difficulties in social interaction. ${ }^{1}$ Among elderly people with age-related macular degeneration, higher levels of depressive symptoms were found compared with their non-impaired peers. ${ }^{2}$ Further, people reported functional limitations in combination with the loss of independence and loss of leisure activities. ${ }^{2}$ A review by Nyman et $a l^{3}$ showed a negative effect of being visually impaired on the psychosocial well-being among those aged 18-59 years. However, no consistent associations were found between visual impairment and increased rates of depression. ${ }^{3}$

The described findings reflect research done among the civilian population whereby the highest prevalence of visual impairment is among elderly and results from non-traumatic causes. However, due to the recent conflicts in Iraq and Afghanistan, combat-related morbidity among younger service personnel returning from conflicts increased. Between July 2004 and May 2008, 630 UK service personnel who were deployed in Iraq or Afghanistan survived a major trauma, of which $10 \%(n=63)$ sustained an ocular injury. ${ }^{4}$

A review summarising the mental health effects of an irreversible impairment among ex-service personnel concluded that common mental health disorders were more prevalent among personnel with an impairment compared with non-impaired personnel; higher rates of post-traumatic stress disorder (PTSD), anxiety, psychological distress and depression were also identified..$^{5}$ The majority of the included studies focused on the impact of a physical impairment on mental well-being. In what way these findings are similar among younger ex-service personnel with a visual impairment is unknown.

The current study examined the mental health of younger ex-servicemen with a visual impairment and determined if the mental health of those with a combat-related visual impairment differed from those whose visual impairment is not combat-related.

\section{METHODS}

\section{Study design and study population}

This cross-sectional study included members of Blind Veterans UK, a charity organisation formerly known as St Dunstan's. Blind Veterans UK provides support and care for (ex-)service personnel who have a visual impairment in both eyes, regardless of the cause. People are eligible to become members of Blind Veterans UK if, at some point, they have 
served in the UK armed forces as a regular or reservist, or served during World War II in the Merchant Navy, or Polish or Indian Forces under British Command. Additionally, they met the sight loss criteria to become members of Blind Veterans UK as assessed by their ophthalmic consultants. Criteria for entry are based on Snellen visual acuity measurement in conjunction with assessment of visual fields. For applicants with central scotomas who retain peripheral vision, people are eligible if they have a Snellen visual acuity of 6/60 or less in the better eye. For applicants with peripheral visual field loss, membership is offered to those with constricted fields irrespective of their Snellen acuity. Their remaining field in the better, or both eyes, should be less than $5^{\circ}$ from fixation.

From the Blind Veterans UK database, two groups of interest were identified:

- Group 1-Combat-related visual impairment: Those who have been visually impaired as a direct result of their service in Operation (Op) TELIC (the conflict in Iraq, 2003-2011), Op HERRICK (the on-going conflict in Afghanistan, 20012014) or due to involvement in another conflict (eg, Northern Ireland).

- Group 2-Non-combat-related visual impairment: Those whose visual impairment is non-combat-related.

Potential participants were included if they were members of Blind Veterans UK, under the age of 55 years as of 1 November 2012, and gave informed consent. Participants were excluded if they lacked the capacity to understand the questions.

\section{Pilot study}

A pilot study was conducted among (ex-)service personnel without a visual impairment $(n=5)$ and members of Blind Veterans UK who exceeded the age threshold $(n=5)$. Consequently, several adaptations were made to the questionnaires and language/terminology used.

\section{Selection procedure}

The initial pool of potential participants consisted of 145 members (figure 1). Based on existing information, three members were withdrawn at the start by Blind Veterans UK. The 142 members received a letter from Blind Veterans UK to inform them about the study and gave them the opportunity to opt out if they did not wish to participate. One participant volunteered to participate but it became evident that he just exceeded the requested age range. This participant was included in the pilot study. The total number of eligible male participants who could be contacted by the research team was 129 .

All male ex-service personnel who became visually impaired during Op TELIC or Op HERRICK were approached to participate $(n=12)$. Furthermore, all men below 45 years of age were selected $(n=38)$, irrespective of their cause of visual impairment. Finally, a random selection of 49 men aged 45-55 years was made (out of $n=78$ ). This particular selection procedure was designed based on the limited numbers of male ex-service personnel who became visually impaired as a result of active military service during Op TELIC or Op HERRICK and our particular

Figure 1 Participant flow diagram.

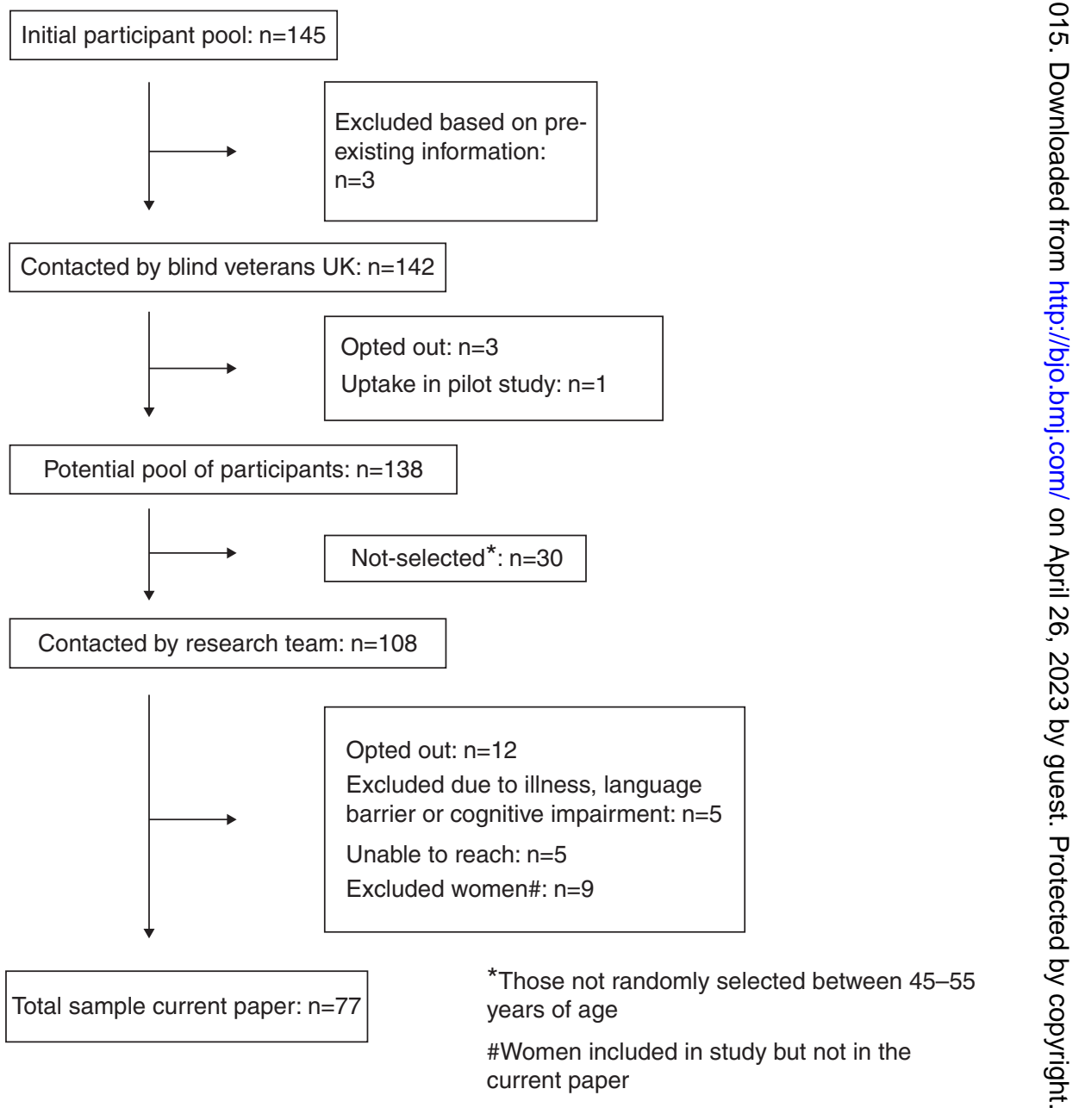


interest in younger personnel. Twelve potential participants were not willing to participate after the research team contacted them and opted out. No differences were identified in relation to age, rank or service type between those who opted out and those who participated in the study (data not shown). Our random selection of participants older than 44 years of age resulted in slightly more participants from the Royal Air Force in the selected group compared with those not selected $(20 \%$ vs $7 \%)$ and less participants who served in the army (62\% vs $73 \%)$.

Members received an invitation by post or email, to participate in the study. After 1 month, a courtesy call was made to check whether members received the information and to answer any queries.

\section{Data collection}

Data were collected by telephone interviews between December 2012 and May 2013. The telephone interviews lasted between 25 and $110 \mathrm{~min}$. Participants received $£ 15$ for their time. Informed consent was obtained verbally at the start of the telephone interview, after detailing the purpose and nature of the study. All telephone interviews were recorded.

\section{Measures}

In addition to questions related to sociodemographic information, service history and general health, participants were asked about their degree of vision loss. The overwhelming majority was not able to provide this information, and this was, therefore, not reported in the current paper. The cause of visual impairment was self-reported by the participant and checked with the diagnosis provided by the ophthalmologist at Blind Veterans UK. All our participants acquired their visual impairment while serving in the UK armed forces. Before joining, possible recruits will undergo a health check including an eye test. Minimum standards for both uncorrected and corrected vision vary between service branch and trade group, but refractive error should not exceed -6 dioptres or +6 dioptres in any meridian. ${ }^{6}$

Further, several validated and widely applied quantitative mental health screening measures were used. The Patient Health Questionnaire is a nine-item depression screening tool to assess mood over the past 2 weeks. ${ }^{7}$ A score of 15 or more was used as an indication of probable depression. ${ }^{7}$ The Generalised Anxiety Disorder Assessment (GAD-7) was used to identify anxiety disorders where a score of 10 or more represented a cut-off point for probable GAD. ${ }^{8}$ The Post-Traumatic Stress Disorder Checklist-Civilian was used to identify symptoms of probable PTSD. ${ }^{9}{ }^{10}$ A cut-off score of 50 or more was used to define probable PTSD. ${ }^{10}$ The 10 -item Alcohol Use Disorders Identification Test was used to identify alcohol misuse. A score between 8 and 15 was classified as hazardous drinking, and 16 or above as harmful drinking. ${ }^{11}$

\section{Statistical analyses}

Data were examined using descriptive analysis. Numbers and percentages are presented for categorical data and means (with SDs) and medians (with IQR) for continuous data. Univariable analyses methods were used including the $\chi^{2}$ tests, Wilcoxon, Mann-Whitney U test and Fisher's exact test; 95\% CIs were calculated for each prevalence estimate. Comparisons were made between those with a combat-related visual impairment and a non-combat-related visual impairment. Additionally, comparisons were made between participants aged 44 years and above, randomly selected and those who were not randomly selected in that age group and, therefore, not invited to take part in our study. We also compared those who agreed to participate in the study with those who declined participation. Data were analysed using STATA statistical software V.11.0.

\section{RESULTS}

We invited 99 men who were eligible to participate and 77 of them agreed, reflecting a response rate of $76.2 \%$. Three participants did not finish the telephone interview so their data were excluded, leaving data for 74 participants for analysis. Of the 74 participants, $20(27.0 \%)$ had a combat-related visual impairment, of whom 10 sustained the impairment during their deployment in Iraq or Afghanistan. Of those visually impaired, but not as a result of combat $(n=54), 18.5 \%$ had a visual impairment caused by ocular complications of a systemic disease (eg, due to diabetes, multiple sclerosis); 22.2\% had a visual impairment caused by ocular pathology without systemic association (eg, age-related macular degeneration, glaucoma, etc), $35.2 \%$ a genetic visual impairment (eg, retinal/macular dystrophies, optic nerve conditions), and in $22.2 \%$ of the cases, the visual impairment was related to environmental causes (eg, toxic or injury related).

\section{Study population characteristics}

The median age was lower in the combat-related visual impairment group than in the non-combat-related visual impairment group (33.5 years vs 47.5 years; $\mathrm{p}<0.01$ ) (table 1 ). In both groups, approximately three in four ex-service personnel had served in the army. Only $20.0 \%$ of those with a combat-related visual impairment reported additional long-term illness or health problems not resulting from the event that caused the visual impairment, compared with $63.0 \%$ of those with a non-combat-related impairment $(p<0.01)$ (table 1$)$.

\section{Presence of probable mental health disorders}

Overall, 28.4\% (95\% CI 18.1 to 38.7) of the participants screened positive for probable depression, probable anxiety or probable PTSD. This was $25.0 \%$ (95\% CI 6.0 to 44.0$)$ in combat-related visually impaired participants and 29.6\% $(95 \%$ CI 17.4 to 41.8 ) in those with a non-combat-related visual impairment (Fisher's exact test $\mathrm{p}=0.80$ ) (data not shown).

A smaller percentage of combat-related visually impaired ex-service personnel screened positive for probable depression or probable PTSD, but a higher percentage screened positive for probable anxiety disorder or fulfilled the criteria for hazardous or harmful drinking than those with a non-combat-related visual impairment. However, these differences were not statistically significant (table 2).

\section{DISCUSSION}

\section{Principal findings}

Our findings suggest that mental health problems are prevalent among younger ex-servicemen with a visual impairment (range 10.0\%-45.0\%). Alcohol problems were most prevalent, followed by probable anxiety disorder, probable PTSD and probable depression. No statistically significant differences were found in the prevalence of mental health problems among ex-servicemen with a combat-related visual impairment compared with those with a non-combat-related visual impairment.

\section{Comparison with the literature}

There are several studies that examined the mental health of the general population as well as of UK armed forces personnel that can be used to compare our findings with. However, it is important to note that all our participants were men, the 
Table 1 Sociodemographic characteristics, military service and health characteristics of younger ex-servicemen with a combat-related visual impairment and younger ex-servicemen with a non-combat-related visual impairment

\begin{tabular}{|c|c|c|c|}
\hline & $\begin{array}{l}\text { Combat-related visual } \\
\text { impairment }(n=20) \\
n(\%)\end{array}$ & $\begin{array}{l}\text { Non-combat-related } \\
\text { visual impairment }(n=54) \\
n(\%)\end{array}$ & $\begin{array}{l}\text { Statistical test, } \\
\text { p value }\end{array}$ \\
\hline Age (years) & $\begin{array}{l}\text { Median: } 33.5 \\
\text { IQR: } 25.5-47.5\end{array}$ & $\begin{array}{l}\text { Median: } 47.5 \\
\text { IQR: } 41-51\end{array}$ & $\mathrm{p}<0.01$ (Wilcoxon-Mann-Whitney) \\
\hline \multicolumn{4}{|l|}{ Marital status } \\
\hline In a relationship & $11(55.0)$ & $33(61.1)$ & \\
\hline Not in a relationship & $9(45.0)$ & $21(38.9)$ & $\begin{array}{l}p=0.63\left(\chi^{2}\right) \\
\chi^{2}(1) 0.23\end{array}$ \\
\hline \multicolumn{4}{|l|}{ Children } \\
\hline Yes & $11(55.0)$ & $42(77.8)$ & \\
\hline No & $9(45.0)$ & $12(22.2)$ & $\begin{array}{l}p=0.05\left(\chi^{2}\right) \\
\chi^{2}(1) 3.73\end{array}$ \\
\hline \multicolumn{4}{|l|}{ Educational qualifications* } \\
\hline None & $1(5.0)$ & $6(11.5)$ & \\
\hline 0 levels or similar & $8(40.0)$ & 20 (38.5) & \\
\hline A levels, similar or higher & $11(55.0)$ & $26(50.0)$ & $\mathrm{p}=0.86$ (Fisher's exact) \\
\hline \multicolumn{4}{|c|}{ Employed at the time of interviewt } \\
\hline Yes & $11(55.0)$ & $15(27.8)$ & \\
\hline No & $9(45.0)$ & $39(72.2)$ & $\begin{array}{l}p=0.03\left(\chi^{2}\right) \\
\chi^{2}(1) 4.75\end{array}$ \\
\hline \multicolumn{4}{|l|}{ Housing } \\
\hline Owned & $14(70.0)$ & $20(37.0)$ & \\
\hline Rented & $5(25.0)$ & $30(55.6)$ & \\
\hline Other & $1(5.0)$ & $4(7.4)$ & $\mathrm{p}=0.04$ (Fisher's exact) \\
\hline \multicolumn{4}{|l|}{ Time in military (years) } \\
\hline $0-4$ & $5(25.0)$ & $13(24.1)$ & \\
\hline $5-12$ & $11(55.0)$ & $28(51.9)$ & \\
\hline$>12$ & $4(20.0)$ & $13(24.1)$ & $\mathrm{p}=1.00$ (Fisher's exact) \\
\hline \multicolumn{4}{|c|}{ Time since becoming visual impaired (years) } \\
\hline & $\begin{array}{l}\text { Median: } 6.3 \\
\text { IQR: } 3.1-20.0\end{array}$ & $\begin{array}{l}\text { Median: } 12.1 \\
\text { IQR: } 6.7-19.6\end{array}$ & $\mathrm{p}=0.35$ (Wilcoxon-Mann-Whitney) \\
\hline $0-4$ years & $7(35.0)$ & $7(13.0)$ & \\
\hline $5-9$ years & $4(20.0)$ & $17(31.5)$ & \\
\hline 10-14 years & $2(10.0)$ & $9(16.7)$ & \\
\hline 15 ore more & $7(35.0)$ & $21(38.9)$ & $\mathrm{p}=0.21$ (Fisher's exact) \\
\hline \multicolumn{4}{|c|}{ Other long-term illness, health problems, but not as result of the event that caused the visual impairment } \\
\hline Yes & $4(20.0)$ & $34(63.0)$ & \\
\hline No & $16(80.0)$ & $20(37.0)$ & $\mathrm{p}<0.01$ (Fisher's exact) \\
\hline \multicolumn{4}{|l|}{ Amputation } \\
\hline Yes & $5(25.0)$ & $0(0.0)$ & \\
\hline No & $15(75.0)$ & $54(100.0)$ & $\mathrm{p}<0.01$ (Fisher's exact) \\
\hline \multicolumn{4}{|l|}{ Currently on medication } \\
\hline Yes & $8(40.0)$ & $35(64.8)$ & \\
\hline No & $12(60.0)$ & $19(35.2)$ & $\begin{array}{l}p=0.06\left(\chi^{2}\right) \\
\chi^{2}(1) 3.70\end{array}$ \\
\hline \multicolumn{4}{|l|}{ Self-rated health } \\
\hline Excellent/very good/good & $18(90.0)$ & $36(66.7)$ & \\
\hline Fair/poor & $2(10.0)$ & $18(33.3)$ & $\mathrm{p}=0.08$ (Fisher's exact) \\
\hline
\end{tabular}

majority had served in the Army and are, on average, older than the UK armed forces population, whereby approximately $90 \%$ is below 44 years of age. ${ }^{12}$

\section{Military populations}

Levels of depression or anxiety among male service personnel who had been deployed on Op TELIC were 11\% (both) and $5 \%$ for PTSD. ${ }^{13}$ Twenty per cent of them reported hazardous or harmful drinking. ${ }^{13}$ This study used a subsample of a larger study carried out among UK service personnel $(n=5743)$, in which $4 \%$ of the men fitted the criteria for PTSD. ${ }^{14}$ Further, their results suggested that higher levels of mental health disorders, especially PTSD, were present among those who had experienced combat during deployment, and reservists. ${ }^{14}$ In our study, participants with a non-combat-related visual impairment reported slightly higher levels of PTSD compared with 
Table 2 Mental health characteristics of younger ex-servicemen with a combat-related visual impairment and younger ex-servicemen with a non-combat-related visual impairment

\begin{tabular}{|c|c|c|c|}
\hline & $\begin{array}{l}\text { Combat-related visual } \\
\text { impairment }(n=20) \\
n(\%)\end{array}$ & $\begin{array}{l}\text { Non-combat-related visual } \\
\text { impairment }(n=54) \\
n(\%)\end{array}$ & $\begin{array}{l}\text { Fisher's exact } \\
\text { test, } p \text { value }\end{array}$ \\
\hline \multicolumn{4}{|l|}{ PHQ (depressive symptomatology) } \\
\hline No probable depression (0-14) & $\begin{array}{l}18(90.0) \\
(95 \% \mathrm{Cl} 76.9 \text { to } 100)\end{array}$ & $\begin{array}{l}44(81.5) \\
(95 \% \mathrm{Cl} 71.1 \text { to } 91.9)\end{array}$ & \\
\hline Probable depression $(\geq 15)$ & $\begin{array}{l}2(10.0) \\
(95 \% \mathrm{Cl} 0 \text { to } 23.2)\end{array}$ & $\begin{array}{l}10(18.5) \\
(95 \% \mathrm{Cl} 8.1 \text { to } 28.9)\end{array}$ & $p=0.49$ \\
\hline \multicolumn{4}{|l|}{ GAD (anxiety symptomatology) } \\
\hline No probable anxiety (0-9) & $\begin{array}{l}15(75.0) \\
(95 \% \mathrm{Cl} 56.0 \text { to } 94.0)\end{array}$ & $\begin{array}{l}44(81.5) \\
(95 \% \mathrm{Cl} 71.1 \text { to } 91.9)\end{array}$ & \\
\hline Probable anxiety $(\geq 10)$ & $\begin{array}{l}5(25.0) \\
(95 \% \text { Cl } 6.0 \text { to } 44.0)\end{array}$ & $\begin{array}{l}10(18.5) \\
(95 \% \mathrm{Cl} 8.1 \text { to } 28.9)\end{array}$ & $p=0.53$ \\
\hline \multicolumn{4}{|l|}{ PCL (PTSD symptomatology) } \\
\hline No probable PTSD (0-49) & $\begin{array}{l}18(90.0) \\
(95 \% \mathrm{Cl} 76.9 \text { to } 100)\end{array}$ & $\begin{array}{l}45(83.3) \\
(95 \% \mathrm{Cl} 73.4 \text { to } 93.3)\end{array}$ & \\
\hline Probable PTSD (>49) & $\begin{array}{l}2(10.0) \\
(95 \% \mathrm{Cl} 0 \text { to } 23.2)\end{array}$ & $\begin{array}{l}9(16.7) \\
(95 \% \text { Cl } 6.8 \text { to } 26.7)\end{array}$ & $p=0.72$ \\
\hline \multicolumn{4}{|l|}{ AUDIT (alcohol problems) } \\
\hline No alcohol problems (0-7) & $\begin{array}{l}7(35.0) \\
(95 \% \mathrm{Cl} 14.1 \text { to } 55.9)\end{array}$ & $\begin{array}{l}34(63.0) \\
(95 \% \mathrm{Cl} 50.1 \text { to } 75.9)\end{array}$ & \\
\hline Hazardous drinking (8-15) & $\begin{array}{l}9(45.0) \\
(95 \% \mathrm{Cl} 23.2 \text { to } 66.8)\end{array}$ & $\begin{array}{l}11(20.4) \\
(95 \% \text { Cl } 9.7 \text { to } 31.2)\end{array}$ & \\
\hline Harmful drinking $(>15)$ & $\begin{array}{l}4(20.0) \\
(95 \% \mathrm{Cl} 2.5 \text { to } 37.5)\end{array}$ & $\begin{array}{l}9(16.7) \\
(95 \% \mathrm{Cl} 6.8 \text { to } 26.7)\end{array}$ & $p=0.07$ \\
\hline
\end{tabular}

combat-related visually impaired personnel. A possible explanation may be the older age of the former group; they have had more time to experience other possible traumatic life events that may have triggered the onset of PTSD. Another explanation might be the possible delayed onset of PTSD. However, so far, there is only limited understanding of the concept of delayed onset PTSD and no consensus has been reached about its existence or prevalence. ${ }^{1516}$ Additionally, a difference in the level of combat-related/deployment-related stressors may partly explain this finding. ${ }^{14}$ However, the differences identified in PTSD levels among the participants by cause of visual impairment were not statistically significant.

\section{Visually impaired populations}

Among 13900 UK elderly aged 75 years and older, 13.5\% of those with a visual impairment fitted the criteria for depression and $9.3 \%$ for anxiety. ${ }^{17}$ According to the authors, the negative impact of visual impairment on daily functioning may lead to symptoms of depression. ${ }^{17}$ In our study, slightly higher levels of depression were found among non-combat-related visually impaired service personnel compared with those with a combat-related visual impairment. This might be partly explained due to higher levels of comorbidity among non-combat-related visually impaired participants, being reflected in more severely impaired daily functioning and impacting on the participant's mood. ${ }^{2}{ }^{17}$ A review conducted by Nyman $e t a l^{3}$ summarising the mental well-being of visually impaired working-age adults, found no robust association between depression and vision impairment. ${ }^{3}$ Also, of the eight studies included in their review, no clear evidence was found that anxiety was higher among people with a visual impairment. ${ }^{3}$ We were unable to identify a study examining the prevalence of PTSD among persons with an acquired visual impairment. Pinquart and Pfeiffer ${ }^{18}$ conducted a meta-analysis focusing on studies that compared psychological well-being in visually impaired participants with normative data or nonimpaired control groups. They concluded that only small to moderate differences were found on measures for psychological well-being and that the majority of the visually impaired people did not have lower levels of well-being, although substantial lower levels were found among individuals with severe vision loss and age-related macular degeneration (AMD). ${ }^{18}$

\section{General populations}

The Adult Psychiatric Morbidity Survey ${ }^{19}$ suggested that 2\% of the UK male population screened positive for probable depression, $4 \%$ for probable anxiety and 3\% for probable PTSD, and one in three of the men reported probable alcohol misuse. In the current study, despite the results not being statistically significant at the 0.05 level $(p=0.07)$, a higher level of alcohol misuse was found in combat-related visually impaired ex-service personnel compared with those with a non-combatrelated visual impairment. A higher number of younger personnel were included in the former group, and findings from other studies suggest that alcohol misuse is more common among younger men. ${ }^{19} 20$ The European Study on the Epidemiology of Mental Disorders found slightly different levels of mental health disorders; $13 \%$ of the men met the criteria for depression and $3 \%$ for both anxiety or PTSD. ${ }^{21}$

In general, our results may indicate higher levels of mental health problems among working-age ex-servicemen compared with the general population as well as military populations, however, we need to be cautious in drawing firm conclusions, as the heterogeneity of the studies was considerable. No significant difference in the presence of mental health problems by cause of visual impairment was found. This might be due to 
methodological limitations of our study, such as the sample size or the lack of information on other variables as outlined above. For example, we were unable to collect information on combat exposure, as participants may have been on operational deployment more than a decade ago and would have had problems to recall this information accurately. Results from the qualitative component of the current study conducted among a subsample of 30 male (ex-)service members with a visual impairment, suggested that those who lost their vision in combat were proud about the circumstances that led to their loss of vision, whereas those with a non-combat-related visual impairment even felt guilty or ashamed (Stevelink et al, submitted). Still, other factors such as the support network of the person affected, coping strategies, and the severity of vision loss may play a more important role into how sustaining a visual impairment may affect the mental well-being of the person affected.

\section{Strengths and limitations}

This study has a number of limitations. The sample size of the current study was small. However, only 138 Blind Veterans UK male members were eligible to participate, of which 99 were actually contacted and 77 were included (response rate 76.2\%). Our survey participants are ex-servicemen with a visual impairment, and all are members of Blind Veterans UK. The generalisability of these findings to visually impaired populations including civilians, ex-servicewomen or ex-service personnel who are not members of this charity organisation, might be limited. Despite these limitations, this study made use of a variety of widely applied and well-validated quantitative mental health screening measures resulting in a detailed insight into the mental well-being of visually impaired younger ex-service men.

\section{Implications and conclusions}

Mental health problems were prevalent among visually impaired younger ex-service men, irrespective of the cause of their visual impairment (combat vs non-combat). It is important that clinicians, ophthalmologists, other health professionals as well as the (wider) family of the person affected are aware that the visual impairment has far reaching consequences and that they need to provide optimal support to the person affected to adjust mentally, physically and socially. Special attention needs to be paid to the mental well-being of the visually impaired person, and research should be directed into best ways of providing support and care to enable the visually impaired person to cope with this, often experienced as traumatic, life-changing event.

Contributors SAMS was involved in the design and planning of the study, participated in data collection, developed the analytical strategy for this paper, undertook the data analyses presented here and wrote the paper. EMM was involved in the design and planning of the study, participated in data collection and commented on the paper. PCG undertook some data analyses and commented on the paper. NTF was involved in the design and planning of the study and commented extensively on the paper.

Funding SAMS and EMM are funded by Blind Veterans UK. NTF is funded by the UK Ministry of Defence. The authors' work was independent of the funders.
Competing interests SAMS, EMM and NTF are based at King's College London, which receives funding from the UK Ministry of Defence (MoD). SAMS and EMM receive funding from Blind Veterans UK to carry out the Blind Veterans UK study. The authors were not directed in any way by the charity or the MoD in relation to this publication.

Ethics approval Ethical approval was given by the Social Care Research Ethics Committee (12-IEC08-0032).

Provenance and peer review Not commissioned; externally peer reviewed.

Open Access This is an Open Access article distributed in accordance with the Creative Commons Attribution Non Commercial (CC BY-NC 4.0) license, which permits others to distribute, remix, adapt, build upon this work non-commercially, and license their derivative works on different terms, provided the original work is properly cited and the use is non-commercial. See: http://creativecommons.org/ licenses/by-nc/4.0/

\section{REFERENCES}

1 Nyman SR, Dibb B, Victor CR, et al. Emotional well-being and adjustment to vision loss in later life: a meta-synthesis of qualitative studies. Disabil Rehabil 2012;34:971-81.

2 Mitchell J, Bradley C. Quality of life in age-related macular degeneration: a review of the literature. Health Qual Life Outcomes 2006;4:97.

3 Nyman SR, Gosney MA, Victor CR. Psychosocial impact of visual impairment in working-age adults. Br J Ophthalmol 2010;94:1427-31.

4 Blanch RJ, Bindra MS, Jacks AS, et al. Ophthalmic injuries in British Armed Forces in Iraq and Afghanistan. Eye 2011;25:218-23.

5 Stevelink SA, Malcolm EM, Mason C, et al. The prevalence of mental health disorders in (ex-)military personnel with a physical impairment: a systematic review. Occup Environ Med 2015;72:243-51.

6 Royal Naval Service. Her Majesty's Naval Service Application Form Guidance Notes. 2013.

7 Kroenke K, Spitzer RL, Williams JB. The PHQ-9: validity of a brief depression severity measure. J Gen Intern Med 2001;16:606-13.

8 Spitzer RL, Kroenke K, Williams JB, et al. A brief measure for assessing generalized anxiety disorder: the GAD-7. Arch Intern Med 2006;166:1092-7.

9 Weathers FW, Litz B, Herman D, et al. The PTSD Checklist (PCL): reliability, validity and diagnostic utility. Annual Meeting of International Society for Traumatic Stress Sudies. San Antonio, TX, 1993.

10 Weathers FW, Huska JA, Keane TM. The PTSD checklist-civilian version (PCL-C). Boston: National Centre for PTSD, 1994.

11 Babor TF, Higgins-Biddle JC, Saunders JB, et al. The alcohol use disorders identification test; guidelines for use in primary care. Geneva: World Health Organization, 2001.

12 Ministry of Defence. UK armed forces annual personnel report. 2014.

13 Iversen AC, van Staden L, Hughes JH, et al. The prevalence of common mental disorders and PTSD in the UK military: using data from a clinical interview-based study. BMC Psychiatry 2009;9:68.

14 Fear NT, Jones M, Murphy $D$, et al. What are the consequences of deployment to Iraq and Afghanistan on the mental health of the UK armed forces? A cohort study. Lancet 2010;375:1783-97.

15 Andrews B, Brewin CR, Philpott $R$, et al. Delayed-onset posttraumatic stress disorder: a systematic review of the evidence. Am J Psychiatry 2007;164:1319-26.

16 McNally RJ. Progress and controversy in the study of posttraumatic stress disorder. Annu Rev Psychol 2003;54:229-52.

17 Evans JR, Fletcher AE, Wormald RP. Depression and anxiety in visually impaired older people. Ophthalmology 2007;114:283-8.

18 Pinquart M, Pfeiffer JP. Psychological well-being in visually impaired and unimpaired individuals: a meta-analysis. British J Vis Impair 2011;29:27-45.

19 NHS Information Centre for Health and Social Care. Adult psychiatric morbidity in England, 2007; results of a household survey, 2009.

20 Fear NT, Iversen A, Meltzer H, et al. Patterns of drinking in the UK Armed Forces. Addiction 2007;102:1749-59.

21 Bernal M, Haro JM, Bernert $S$, et al. Risk factors for suicidality in Europe: results from the ESEMED study. J Affect Disord 2007;101:27-34. 